\section{(6) OPEN ACCESS}

\title{
We have the programme, what next? Planning the implementation of an injury prevention programme
}

\author{
Alex Donaldson, ${ }^{1}$ David G Lloyd, ${ }^{2}$ Belinda J Gabbe, ${ }^{3}$ Jill Cook $_{,}{ }^{4}$ Caroline F Finch $^{1}$
}

\begin{abstract}
${ }^{1}$ Australian Centre for Research into Injury in Sport and its Prevention (ACRISP), Federation University Australia, Ballarat, Victoria, Australia

${ }^{2}$ Centre for Musculoskeletal Research, Menzies Health Institute Queensland, Griffith University, Queensland,

Australia

${ }^{3}$ Department of Epidemiology and Preventive Medicine, Monash UniversityEpidemiology and Preventive Medicine, Monash University The Alfred Centre, Melbourne, Victoria, Australia

${ }^{4}$ Monash University, Melbourne, Victoria, Australia
\end{abstract}

\section{Correspondence to}

Prof. Caroline Finch, Australian Centre for Research into Injury in Sport and its Prevention (ACRISP), Federation University Australia, P.0. Box 663, Ballarat, VIC 3353, Australia; c.finch@ federation.edu.au

Received 23 June 2015 Revised 17 November 2015 Accepted 28 November 2015 Published Online First 19 January 2016

\section{ABSTRACT}

Background and aim The impact of any injury prevention programme is a function of the programme and its implementation. However, real world implementation of injury prevention programmes is challenging. Lower limb injuries (LLIS) are common in community Australian football (community-AF) and it is likely that many could be prevented by implementing exercise-based warm-up programmes for players. This paper describes a systematic, evidence-informed approach used to develop the implementation plan for a LLI prevention programme in community-AF in Victoria, Australia.

Methods An ecological approach, using Step 5 of the Intervention Mapping health promotion programme planning protocol, was taken.

Results An implementation advisory group was established to ensure the implementation plan and associated strategies were relevant to the local context. Coaches were identified as the primary programme adopters and implementers within an ecological system including players, other coaches, first-aid providers, and club and league administrators. Social Cognitive Theory was used to identify likely determinants of programme reach, adoption and implementation among coaches (eg, knowledge, beliefs, skills and environment). Diffusion of Innovations theory, the Implementation Drivers framework and available research evidence were used to identify potential implementation strategies including the use of multiple communication channels, programme resources, coach education and mentoring. Conclusions A strategic evidence-informed approach to implementing interventions will help maximise their population impact. The approach to implementation planning described in this study relied on an effective researcher-practitioner partnership and active engagement of stakeholders. The identified implementation strategies were informed by theory, evidence and an in-depth understanding of the implementation context.

\section{INTRODUCTION}

The need for implementation planning

Injury prevention programmes have little population health impact if they are not evidence-based and used widely. ${ }^{1}$ Programme effects have been shown to be up to three times higher when programmes are well implemented. ${ }^{2}$ Without a systematic and evidence-informed approach to programme implementation, conclusions of limited effectiveness will be made based on poor implementation. $^{3}$ Structured implementation planning frameworks can help to reduce the research-to-practice gap and maximise programme impact by increasing the use of evidenced-based programmes in communities. ${ }^{4} 5$

Sports-related injuries are a significant public health problem ${ }^{6}$ requiring a systematic approach to their prevention. This should include quantifying the injury problem, identifying the causes and risk factors, developing and trialling interventions and developing implementation strategies to enable evidence-based interventions to be effective in real world settings. ${ }^{1}$ To date, research across a range of sports, in several countries, suggests that, although evidence-based sports injury prevention interventions are available, they are generally neither widely nor well implemented at the elite, community or school level. $^{7-11}$

There have been few published implementation or effectiveness studies in sports injury prevention $^{12}$ and information about specific implementation components is scarce. ${ }^{13}$ Similarly, the evidence or theory underpinning implementation strategies used in sports injury prevention trials are rarely reported. $^{14}$

\section{Community Australian football: injury epidemiology and relevant countermeasures} Australian football (AF) is a popular community/ recreational participation sport in Australia with a relatively high risk and rate of injury. ${ }^{15}{ }^{16}$ Lower limb injuries (LLIs) are common in community$\mathrm{AF}^{17}$ despite the fact that many are potentially preventable. $^{18}$

A recent review of LLI prevention exercise protocols concluded that an exercise-based warm-up programme including balance and control, eccentric hamstring, plyometric and strength exercises could prevent LLIs in community-AF. ${ }^{18}$ In response, as part of the larger National Guidance for Australian football Partnerships and Safety (NoGAPS) project, ${ }^{19}$ a LLI prevention programme (FootyFirst) targeted at male, adult community-AF players was developed. The exercises included in FootyFirst were underpinned by research evidence, ${ }^{18}{ }^{20}$ expert opinion $^{21}$ and a randomised controlled trial evaluation of a precursor programme which demonstrated clinically important reductions in lower limb (22\%) and knee (50\%) injury rates. ${ }^{22}$ FootyFirst was developed anticipating that it would become a national programme after being trialled in three geographical regions of Victoria, Australia.

To address the research-to-practice gap in the general and sports-specific injury prevention literature, ${ }^{7} 23$ this paper describes the development of an implementation plan for FootyFirst in one arm of the larger NoGAPS study. It also provides general guidance to injury prevention practitioners and 
researchers in how to plan the implementation of interventions in any context.

\section{METHODS}

Intervention Mapping (IM) facilitates effective health promotion programme planning, implementation and evaluation. ${ }^{24}$ IM Step 5, which can be used independently of other IM steps, focuses on planning programme adoption, implementation and maintenance. ${ }^{24}$ It comprises seven tasks that are operationalised through six core processes.

Building on previous sports safety programme implementation planning research, ${ }^{25}$ we used IM Step 5 to plan the implementation of FootyFirst in a regional AF league ( $n=22$ clubs) in Victoria, Australia. The IM Step 5 tasks undertaken, and the key questions addressed during the implementation planning, are outlined in table 1.

The seven-person league-specific FootyFirst Implementation Advisory Group (IAG) established in Task 2 comprised the project manager (author $\mathrm{AD}$ ), a league administrator, a regional game development officer, a community club administrator, two community club senior coaches and a community club high performance manager (who was also a player). The IAG participated in IM Step 5 Tasks 3-7 using the six IM core processesposing questions, brainstorming, reviewing the literature, using theory, acquiring new data and formulating answers ${ }^{24}$ - to help complete each task.

FootyFirst is ultimately targeted at recreational adult, male AF players (typically aged between 18 years and 35 years) who generally train twice and play one game of football each week. However, because the training of these players is the responsibility of community-AF club coaches, the implementation activities were directed at the senior coaches of all 22 community-AF clubs in one geographical region, where the competition was administered by a single governing league. Implementation planning was undertaken in October-December 2011 with the aim of operationalising the strategies during the 2012 communityAF season.

\section{RESULTS}

The outcomes of the seven tasks of IM Step 5, as they applied to planning the implementation of FootyFirst, are summarised in tables 2-4.

Table 1 How the Intervention Mapping Step 5 tasks were applied when planning the implementation of FootyFirst

\begin{tabular}{ll}
\hline Intervention Mapping Step 5 Task \\
\hline Task $1 \quad \begin{array}{l}\text { Identify potential FootyFirst adopters and } \\
\text { implementers }\end{array}$ \\
Task 2 Establish a FootyFirst implementation \\
$\begin{array}{l}\text { planning group with representatives of } \\
\text { potential FootyFirst adopters and } \\
\text { implementers }\end{array}$
\end{tabular}

Task 3 State FootyFirst use outcomes and specify performance objectives

Task 4 Specify determinants of FootyFirst reach, adoption and implementation

Task 5 Identify change objectives for FootyFirst reach, adoption and implementation reach, adoption and implementation

Purpose

To identify individuals and organisations that would be involved in, or would influence, FootyFirst adoption and implementation by community-AF coaches within the targeted league

To link FootyFirst developers (ie, the project team) to programme adopters/implementers (ie, coaches)

To describe what the implementation activities should accomplish including who had to do what for coaches to be reached and FootyFirst to be adopted and implemented

To identify what will influence whether or not coaches performed the actions needed to accomplish the performance objectives.

To link FootyFirst reach, adoption and implementation performance objectives and determinants, to create change objectives

To identify specific strategies to achieve the change objectives context-specific FootyFirst reach, adoption and implementation strategies

Task 7 Design interventions for FootyFirst reach, adoption and implementation
Application and key questions in the FootyFirst implementation planning project

Key question: "Who will decide to use FootyFirst and who will actually deliver FootyFirst to the players?" The ecological context (eg, team, club, league) in which FootyFirst was to be adopted and implemented was considered

A league-specific FootyFirst Implementation Advisory Group (IAG) was established including representatives of the project team and community-AF coaches, and 'change agents' (eg, league/club administrators) who could influence the FootyFirst adoption and implementation decisions and behaviours

Key question: "What do community-AF coaches need to do to constitute FootyFirst adoption and implementation of coaches?"

Key question: "What is likely to influence whether coaches adopt and implement FootyFirst?"

Key question: "What is it about the determinants (from Task 4) that need to change for coaches to achieve the performance objectives (from Task 3)?" FootyFirst reach adoption and implementation matrices were created. Change objectives were developed by assessing matrix cells to explore whether the identified determinant was likely to influence accomplishment of the relevant performance objective

Key question: "What could be done to help, support or encourage coaches to achieve the agreed change objectives?" To ensure that proposed strategies had some basis in evidence, theory or experience, also asked: "Why is a particular implementation strategy likely to work?" Theory-informed and evidence-informed strategies were selected based on perceived capacity to create change in the determinants and knowledge of the implementation context

Generated a set of evidence-base, theory-informed, context-relevant activities and resources that reflected the thinking and planning done in Task 1-6 that, when undertaken, should lead to improved FootyFirst reach, adoption and implementation by community-AF coaches 
Table 2 Performance objectives, determinants and change objectives for the Reach of FootyFirst among community AF coaches

\begin{tabular}{|c|c|c|c|c|c|c|c|}
\hline \multirow{2}{*}{\multicolumn{2}{|c|}{ Performance objectives (POs) }} & \multicolumn{6}{|c|}{ Determinants of FootyFirst REACH to community Australian football coaches } \\
\hline & & \multicolumn{2}{|c|}{ What is communicated } & \multicolumn{2}{|c|}{ Who is communicating } & \multicolumn{2}{|c|}{$\begin{array}{l}\text { What communication } \\
\text { channels are used }\end{array}$} \\
\hline \multirow[t]{3}{*}{ P01 } & \multirow{3}{*}{$\begin{array}{l}\text { Coaches receive } \\
\text { information about } \\
\text { FootyFirst }\end{array}$} & $\mathrm{C} 1$ & $\begin{array}{l}\text { Know lower limb injuries have negative } \\
\text { impact on individual and team performance }\end{array}$ & $\mathrm{C} 4$ & $\begin{array}{l}\text { Believe FootyFirst information is } \\
\text { coming from a credible source }\end{array}$ & $\mathrm{C} 7$ & $\begin{array}{l}\text { Receive communication in an } \\
\text { acceptable format }\end{array}$ \\
\hline & & $\mathrm{C} 2$ & $\begin{array}{l}\text { Know FootyFirst is effective in preventing } \\
\text { lower limb injuries }\end{array}$ & C5 & $\begin{array}{l}\text { Receive FootyFirst information from } \\
\text { a familiar source }\end{array}$ & $\mathrm{C} 8$ & $\begin{array}{l}\text { Receive communication in a } \\
\text { familiar way }\end{array}$ \\
\hline & & C3 & Know FootyFirst is specific to community-AF & $\mathrm{C} 6$ & $\begin{array}{l}\text { Receive FootyFirst information from } \\
\text { a variety of sources }\end{array}$ & C9 & $\begin{array}{l}\text { Receive FootyFirst information } \\
\text { in a variety of ways }\end{array}$ \\
\hline
\end{tabular}

Programme use Reach outcome: coaches are aware of FootyFirst.

AF, Australian football; C1-9, communication change objectives.

\section{Task 1: Identifying potential FootyFirst adopters and implementers}

Given the nature of FootyFirst as a programme, ${ }^{21}$ and the role of AF coaches in training players to participate safely, ${ }^{8}$ the senior coaches of the targeted clubs were identified as the primary focus of the implementation activities. Acknowledging the ecological influences on safety programme implementation in community sport ${ }^{26}$ state, regional and club administrators, and community coaches, first aid/rehabilitation providers and players, were identified as potential influences on the FootyFirst implementation decisions and behaviour of senior coaches.
Task 2: Establishing a FootyFirst adoption and implementation planning group

Like many sports, community-AF has a hierarchical, top-down model of delivery. ${ }^{27}$ To leverage this administrative structure, and to obtain high-level support to implement FootyFirst, the project team started Task 2 by gaining national and state-level AF administrators' endorsement of the project. This was achieved by highlighting that: LLIs are a significant problem in community-AF, ${ }^{17}$ an evidence-based training protocol could potentially prevent common community-AF LLIs ${ }^{18}$ and that injury prevention interventions are only worthwhile if they are widely and well implemented. ${ }^{1}$

Table 3 Performance objectives, determinants and change objectives for the Adoption of FootyFirst by community-AF coaches

\begin{tabular}{|c|c|c|c|c|c|c|c|c|c|}
\hline \multirow{3}{*}{\multicolumn{2}{|c|}{$\begin{array}{l}\text { Performance } \\
\text { objectives (POs) }\end{array}$}} & \multicolumn{8}{|c|}{ Determinants of FootyFirst ADOPTION by community-AF coaches } \\
\hline & & \multicolumn{6}{|c|}{ Internal (personal) determinants } & \multicolumn{2}{|c|}{ External determinants } \\
\hline & & \multicolumn{2}{|c|}{ Knowledge } & \multicolumn{2}{|c|}{ Skills } & \multicolumn{2}{|c|}{ Beliefs } & \multicolumn{2}{|c|}{ Environment } \\
\hline \multirow[t]{2}{*}{ PO 2} & $\begin{array}{l}\text { Coaches aware of } \\
\text { need to implement } \\
\text { FootyFirst }\end{array}$ & K1 & $\begin{array}{l}\text { Know why players } \\
\text { should participate in } \\
\text { FootyFirst }\end{array}$ & & & B1 & $\begin{array}{l}\text { Believe lower limb injuries } \\
\text { have a negative impact on } \\
\text { team performance }\end{array}$ & E1 & $\begin{array}{l}\text { Receive information from } \\
\text { respected external sources about } \\
\text { the importance of preventing } \\
\text { lower limb injuries }\end{array}$ \\
\hline & & & & & & $\begin{array}{l}\text { B2 } \\
\text { B3 }\end{array}$ & $\begin{array}{l}\text { Believe team will benefit from } \\
\text { participating in FootyFirst } \\
\text { Believe FootyFirst will reduce } \\
\text { the risk of lower limb injuries }\end{array}$ & & \\
\hline PO 3 & $\begin{array}{l}\text { Coaches access } \\
\text { FootyFirst } \\
\text { resources and } \\
\text { training }\end{array}$ & $\mathrm{K} 2$ & $\begin{array}{l}\text { Know how to access } \\
\text { FootyFirst resources } \\
\text { and training }\end{array}$ & & & B4 & $\begin{array}{l}\text { Believe accessing FootyFirst } \\
\text { resources and training will } \\
\text { increase capacity to implement } \\
\text { FootyFirst }\end{array}$ & E2 & $\begin{array}{l}\text { Receive FootyFirst resources and } \\
\text { training in convenient and } \\
\text { accessible format, time location, } \\
\text { cost, etc }\end{array}$ \\
\hline \multirow[t]{4}{*}{ PO 4} & $\begin{array}{l}\text { Coaches make } \\
\text { decision to } \\
\text { implement }\end{array}$ & K3 & $\begin{array}{l}\text { Know what to do } \\
\text { when implementing } \\
\text { FootyFirst }\end{array}$ & S1 & $\begin{array}{l}\text { Have skills to } \\
\text { implement FootyFirst }\end{array}$ & B5 & $\begin{array}{l}\text { Believe implementing } \\
\text { FootyFirst will lead to relevant } \\
\text { benefits }\end{array}$ & E3 & $\begin{array}{l}\text { Receive external support and } \\
\text { encouragement to implement } \\
\text { FootyFirst }\end{array}$ \\
\hline & FootyFirst & K4 & $\begin{array}{l}\text { Know how to } \\
\text { implement FootyFirst }\end{array}$ & S2 & $\begin{array}{l}\text { Have skills to assess } \\
\text { and correct FootyFirst } \\
\text { exercise techniques }\end{array}$ & B6 & $\begin{array}{l}\text { Believe FootyFirst is more } \\
\text { beneficial than current } \\
\text { warm-up activities }\end{array}$ & E4 & $\begin{array}{l}\text { FootyFirst is compatible with } \\
\text { existing external environmental } \\
\text { conditions }\end{array}$ \\
\hline & & & & & & B7 & $\begin{array}{l}\text { Believe respected others think } \\
\text { implementing FootyFirst is a } \\
\text { good idea }\end{array}$ & E5 & $\begin{array}{l}\text { Have access to equipment } \\
\text { necessary to implement FootyFirst }\end{array}$ \\
\hline & & & & & & & & E6 & $\begin{array}{l}\text { See respected others implementing } \\
\text { FootyFirst or similar program }\end{array}$ \\
\hline \multirow[t]{3}{*}{ PO 5} & $\begin{array}{l}\text { Coaches } \\
\text { implement } \\
\text { FootyFirst }\end{array}$ & $\mathrm{K} 5$ & $\begin{array}{l}\text { Know what to do } \\
\text { when implementing } \\
\text { FootyFirst }\end{array}$ & S3 & $\begin{array}{l}\text { Have skills to } \\
\text { implement FootyFirst } \\
\text { with players }\end{array}$ & B8 & $\begin{array}{l}\text { Believe players would be } \\
\text { willing to participate in } \\
\text { FootyFirst }\end{array}$ & E7 & $\begin{array}{l}\text { Receive external praise and } \\
\text { encouragement for implementing } \\
\text { FootyFirst }\end{array}$ \\
\hline & & K6 & $\begin{array}{l}\text { Know how to } \\
\text { implement FootyFirst }\end{array}$ & & & B9 & $\begin{array}{l}\text { Believe players have capacity } \\
\text { to participate in FootyFirst }\end{array}$ & E8 & $\begin{array}{l}\text { Have access to equipment } \\
\text { necessary to implement FootyFirst }\end{array}$ \\
\hline & & & & & & B10 & $\begin{array}{l}\text { Believe other coaches will } \\
\text { implement FootyFirst }\end{array}$ & & \\
\hline
\end{tabular}

Programme use Adoption outcome: coaches deliver FootyFirst.

AF, Australian football; B1-10 belief change objectives: E1-8, environment change objectives; K1-6, knowledge change objectives; S1-3, skill change objectives. 
Table 4 Performance objectives, determinants and change objectives for the Implementation of FootyFirst by community-AF coaches

\begin{tabular}{|c|c|c|c|c|c|c|c|c|c|}
\hline \multirow{3}{*}{\multicolumn{2}{|c|}{ Performance objectives (POs) }} & \multicolumn{6}{|c|}{ Determinants of FootyFirst IMPLEMENTATION by community-AF coaches } & \multirow{2}{*}{\multicolumn{2}{|c|}{ External determinants }} \\
\hline & & \multicolumn{6}{|c|}{ Internal (personal) determinants } & & \\
\hline & & Knov & ledge & Skill & & Belie & & \multicolumn{2}{|c|}{ Environment } \\
\hline \multirow[t]{4}{*}{ PO 6} & $\begin{array}{l}\text { Coaches incorporate } \\
\text { FootyFirst into regular } \\
\text { warm-up for all training } \\
\text { sessions }\end{array}$ & K7 & $\begin{array}{l}\text { Know what to do } \\
\text { when implementing } \\
\text { FootyFirst regularly } \\
\text { and properly }\end{array}$ & S4 & $\begin{array}{l}\text { Have skills to } \\
\text { implement FootyFirst } \\
\text { regularly and } \\
\text { properly }\end{array}$ & B11 & $\begin{array}{l}\text { Believe that players need to } \\
\text { do FootyFirst regularly and } \\
\text { properly to receive benefits }\end{array}$ & E9 & $\begin{array}{l}\text { Receive external praise and } \\
\text { encouragement for } \\
\text { incorporating FootyFirst into } \\
\text { regular warm-up }\end{array}$ \\
\hline & & K8 & $\begin{array}{l}\text { Know how to } \\
\text { implement FootyFirst } \\
\text { regularly and properly }\end{array}$ & & & B12 & $\begin{array}{l}\text { Believe that incorporating } \\
\text { FootyFirst into warm-up will } \\
\text { lead to players performing } \\
\text { FootyFirst regularly }\end{array}$ & E10 & $\begin{array}{l}\text { Receive external support to } \\
\text { incorporate FootyFirst into } \\
\text { regular warm-up }\end{array}$ \\
\hline & & & & & & B13 & $\begin{array}{l}\text { Believe that other coaches } \\
\text { will incorporate FootyFirst } \\
\text { into warm-up }\end{array}$ & E11 & $\begin{array}{l}\text { Receive external feedback } \\
\text { that players participating in } \\
\text { FootyFirst regularly and } \\
\text { properly is leading to relevant } \\
\text { benefits }\end{array}$ \\
\hline & & & & & & B14 & $\begin{array}{l}\text { Believe players will support } \\
\text { FootyFirst being incorporated } \\
\text { into regular warm-up }\end{array}$ & & \\
\hline \multirow[t]{2}{*}{ PO 7} & $\begin{array}{l}\text { Coaches ensure players } \\
\text { do FootyFirst with } \\
\text { fidelity (ie, appropriate } \\
\text { volume, technique and }\end{array}$ & K9 & $\begin{array}{l}\text { Know what is } \\
\text { required to do } \\
\text { FootyFirst with fidelity }\end{array}$ & S5 & $\begin{array}{l}\text { Have skills to assess } \\
\text { player performance } \\
\text { of FootyFirst }\end{array}$ & B15 & $\begin{array}{l}\text { Believe that players need to } \\
\text { do FootyFirst with fidelity to } \\
\text { receive injury prevention and } \\
\text { performance benefits }\end{array}$ & E12 & $\begin{array}{l}\text { Receive praise and } \\
\text { encouragement from club, } \\
\text { league for players doing } \\
\text { FootyFirst with fidelity }\end{array}$ \\
\hline & intensity) & & & S6 & $\begin{array}{l}\text { Have skills to correct } \\
\text { poor performance of } \\
\text { FootyFirst by players }\end{array}$ & B16 & $\begin{array}{l}\text { Believe that correcting poor } \\
\text { performance of FootyFirst by } \\
\text { players will lead to players } \\
\text { performing FootyFirst with } \\
\text { fidelity }\end{array}$ & E13 & $\begin{array}{l}\text { Receive support from club, } \\
\text { league, etc, for players to do } \\
\text { FootyFirst with fidelity }\end{array}$ \\
\hline \multirow[t]{2}{*}{ PO 8} & $\begin{array}{l}\text { Coaches progress } \\
\text { players through } \\
\text { FootyFirst levels as } \\
\text { appropriate }\end{array}$ & K10 & $\begin{array}{l}\text { Know when to } \\
\text { progress players to } \\
\text { next FootyFirst level }\end{array}$ & S7 & $\begin{array}{l}\text { Have skills to assess } \\
\text { player readiness to } \\
\text { progress to next level } \\
\text { of FootyFirst }\end{array}$ & B17 & $\begin{array}{l}\text { Believe that player } \\
\text { progression through levels of } \\
\text { FootyFirst is required to } \\
\text { maximise injury prevention } \\
\text { and performance benefits }\end{array}$ & E14 & $\begin{array}{l}\text { Receive praise and } \\
\text { encouragement from club, } \\
\text { league for progressing players } \\
\text { through FootyFirst levels }\end{array}$ \\
\hline & & K11 & $\begin{array}{l}\text { Know how to } \\
\text { progress players to } \\
\text { next FootyFirst level }\end{array}$ & S8 & $\begin{array}{l}\text { Have skills to } \\
\text { implement all levels } \\
\text { of FootyFirst }\end{array}$ & & & E15 & $\begin{array}{l}\text { Receive feedback from } \\
\text { players that they are happy to } \\
\text { progress through FootyFirst } \\
\text { levels }\end{array}$ \\
\hline
\end{tabular}

Programme use Implementation outcome: coaches deliver FootyFirst as intended.

AF, Australian football; B11-17, belief change objectives: E9-15, environment change objectives. K7-11, knowledge change objectives; S4-8, skill change objectives.

This was followed by regional/league-level endorsement and active participation by the league administrators to recruit influential local AF coaches and other 'change agents' to join a league-specific FootyFirst IAG. This group linked the programme developers (the project team) to the programme adopters and implementers (the coaches). Specifically, the IAG provided feedback on the FootyFirst performance and change objectives (Tasks 3 and 5) and contributed to identifying the determinants of FootyFirst reach, adoption and implementation (Task 4). They also brainstormed implementation strategies (Tasks 6 and 7) and provided insight into the context and target audience for FootyFirst implementation.

Only the individual (coach), interpersonal (team/players/ other coaches) and organisational (club/league) ecological levels were considered. ${ }^{26}$ This reflects the significant role that the local context plays in sports policy interpretation and implementation. ${ }^{27}$

\section{Task 3: Stating FootyFirst implementation outcomes and} reach, adoption and implementation performance objectives The anticipated implementation outcomes were that coaches would: (1) be aware of FootyFirst (reach); (2) deliver FootyFirst to their players (adoption); and (3) deliver FootyFirst to their players as the programme was intended to be delivered (implementation).
The project team developed performance objectives by defining what constituted FootyFirst reach, adoption and implementation among community-AF coaches. The performance objective for programme reach revolved around coaches becoming aware of FootyFirst through promotional, communication and educational activities, and resource distribution (table 2). Programme adoption performance objectives focused on coaches making the decision to deliver, and actually delivering FootyFirst to their players (table 3). Programme implementation performance objectives reflected that regular and high fidelity player performance of FootyFirst would require coaches to incorporate FootyFirst into the routine warm-up performed by their players at every preseason and regular season training session (table 4). The performance objectives were presented to, and endorsed by, the IAG.

\section{Task 4: Specifying determinants of FootyFirst reach, adoption and implementation}

The IAG concluded that coach awareness of FootyFirst would be influenced by the information communicated about FootyFirst (ie, the message), who communicated the information (ie, the messenger) and the communication channels used (ie, the media used) (table 2). It was agreed that coach adoption and implementation behaviours could be influenced by personal/individual, organisational, social and environmental 
factors. This reflects the major concepts of Social Cognitive Theory (SCT) and the idea that an individual's behaviour is dynamic and a function of the interaction between their personal characteristics and the physical and social environments. ${ }^{28}$ Based on discussions with the IAG, coach knowledge, skills and beliefs, and the team, club and league environments were identified as key determinants of the FootyFirst adoption and implementation behaviour of coaches (tables 3 and 4).

The outcomes of Tasks 3 and 4 were used to construct matrices of FootyFirst reach, adoption and implementation performance objectives and determinants (tables 2-4). Completing these matrices by specifying the FootyFirst reach, adoption and implementation change objectives was undertaken in Task 5.

\section{Task 5: Identifying change objectives for FootyFirst reach, adoption and implementation}

Conceptually, the content of each cell in tables 2-4 represents a desired outcome or change in either the internal/personal (eg, knowledge, skills and beliefs) or external/environmental determinants of the FootyFirst-related knowledge and behaviour of coaches. Because the identified determinants are dynamic and interdependent, no cell is self-contained or limited. For example, a coach's skill in implementing FootyFirst is directly related to, and influenced by, their knowledge of FootyFirst and the fit between FootyFirst and their particular club environment (time, space, equipment, player attitude, etc). The change objectives were presented to, and endorsed by, the IAG.

\section{Tasks 6 and 7: Selecting theory-informed, evidence-based and context-specific FootyFirst reach, adoption and implementation strategies}

The IAG brainstormed potential strategies to facilitate coaches achieving the change objectives identified in Task 5 . The project team reviewed the brainstormed strategies based on available evidence from the research literature, relevant health promotion, injury prevention and implementation science frameworks and theories, and practical context-specific considerations (eg, available budget and resources, workloads, time constraints and preferred communication methods).

Previous studies of coach uptake of injury prevention interventions show that comprehensive coach education can positively influence safety knowledge ${ }^{29}$ and programme implementation behaviour. ${ }^{30}$ Coaches are also more likely to implement injury prevention training if they have access to ideas about how to deliver such training to their players. ${ }^{31}$ The lessons learned from implementing injury prevention programmes in other sports were also used to inform implementation strategy selection. 253233

Although the use of theories and frameworks can enhance programme implementation, ${ }^{34}$ this can be daunting for nonacademics. ${ }^{35}$ We used the Diffusion of Innovations (DOI) theory $^{36}$ and the Implementation Drivers (ID) framework ${ }^{37}$ to guide the review of the brainstormed implementation strategies, based on the recent successful application of both these frameworks in community sport settings. ${ }^{25} 38$ The aspects of DOI considered when reviewing the FootyFirst implementation strategies included: interpersonal and mass media communication channels; opinion leaders and change agents; compatibility with existing practice, culture and values; the relative advantage over existing practices; and the complexity of FootyFirst. ${ }^{36}$ The ID components considered focused on the need to: build coach competency in implementing FootyFirst (eg, coach education delivered in the preseason, at a local venue by a high profile, local high performance coach); build organisational and administrative systems to support FootyFirst implementation (eg, injury surveillance system); and provide leadership for FootyFirst implementation (eg, club presidents publicly committing to implement FootyFirst). ${ }^{14}$

The strategies developed to support FootyFirst reach, adoption and implementation among community-AF coaches, the change objectives these strategies were designed to address, and the DOI and ID framework components used to inform these strategies, are outlined in table 5 . Some strategies, such as distributing FootyFirst resources to coaches, were selected or designed to address multiple change objectives.

\section{DISCUSSION}

Poor programme adoption and use are often a precursor to poor programme outcomes. ${ }^{24}$ This paper describes the systematic and iterative process used to develop an implementation plan for an LLI prevention programme in community-AF. The process was based on a partnership between health promotion, implementation science, and injury prevention researchers, and community sports administrators and coaches. The approach was informed by behaviour change theory, implementation science frameworks and published evidence about effective implementation strategies for safety programmes in community sport. This was supplemented with in-depth knowledge of the implementation context and input from the programme end users.

Creating implementation structures is one of the four phases believed to facilitate high quality implementation of any innovation. ${ }^{39}$ Using IM Step 5, we were able to complete two key steps in this phase-establishing an implementation team and developing an implementation plan ${ }^{39}$-successfully. In conjunction with a strong researcher-practitioner partnership and a structured method of engaging with programme end users, this enabled the development of an implementation plan specifically designed to bridge the gap between research (top-down) and community (bottom-up) driven programme implementation processes.

Future advances in injury prevention are unlikely to be achieved at a population level without a better understanding of how to implement evidence-based interventions in the real world. In the community sport context, achieving widespread implementation of safety programmes is challenging ${ }^{12733}$ and few examples of theory-informed implementation planning are available. 253840

Much of the implementation planning for FootyFirst focused on developing strategies to improve the fit between the programme and the $\mathrm{AF}$ coaches who would need to implement it. This process was greatly enhanced by having representatives from multiple ecological levels-including regional, league and club administrators and community-AF coaches-on the IAG. This ensured that the selected implementation strategies were likely to be doable and sustainable within the constraints and context of the league's administration beyond the life of the funded project.

Considerable attention was given to creating supportive and encouraging environments for implementing FootyFirst in the targeted football clubs. This included involving league and club administrators, and well known and respected community and elite level coaches, in the selection and operationalising of the FootyFirst implementation strategies. Based on previous research developing and implementing sports injury prevention initiatives in the US military, ${ }^{41}$ we anticipated that ensuring FootyFirst was 
Table 5 Implementation strategies developed to enhance the Reach, Adoption and Implementation of FootyFirst among community-AF coaches

Reach

performance objectives: P01*

\begin{tabular}{|c|c|c|}
\hline Change objectives & Implementation strategies & Theoretical construct used to inform strategy development \\
\hline $\begin{array}{l}\text { What is communicated } \\
(\mathrm{C} 1-\mathrm{C} 3) \dagger \\
\text { Who is communicating } \\
(\mathrm{C} 4-\mathrm{C} 6) \dagger \\
\text { What communication } \\
\text { channels are } \\
\text { being used (C7-C9) } \dagger\end{array}$ & $\begin{array}{l}\text { Endorsement of FootyFirst by administrators at state, regional and local } \\
\text { levels } \\
\text { Budget allocation to League to cover costs of FootyFirst } \\
\text { implementation strategies } \\
\text { High profile public launch of FootyFirst } \\
\text { Direct emailing to senior coaches from } \\
\text { - FootyFirst Implementation Advisory Group } \\
\text { - League } \\
\text { Direct emailing to club presidents from: } \\
\text { - FootyFirst Implementation Advisory Group } \\
\text { - League } \\
\text { Personal phone calls and texts to senior coaches from } \\
\text { - FootyFirst Implementation Advisory Group } \\
\text { - Face-to-face meetings with coaches } \\
\text { FootyFirst-related articles in local newspaper and local football-specific } \\
\text { publications }\end{array}$ & $\begin{array}{l}\text { Compatibility: use of usual and preferred communications } \\
\text { channels (DOI) } \\
\text { Compatibility: emphasis on similarity and fit between FootyFirst } \\
\text { and existing practices, available resources etc (DOI) } \\
\text { Multiple communication channels: use of mass media and } \\
\text { interpersonal communication channels (DOI) } \\
\text { Relative advantage: identification and promotion of relative } \\
\text { advantage (over current practices) of coaches delivering FootyFirst } \\
\text { to players (DOI) } \\
\text { Complexity: emphasis on ease of delivery of FootyFirst by } \\
\text { coaches (DOI) } \\
\text { Opinion leaders: high profile, respected and locally relevant } \\
\text { spokespeople used at launch (DOI) } \\
\text { Leadership driver: adaptive leadership at league and club } \\
\text { levels (ID) }\end{array}$ \\
\hline
\end{tabular}

Adoption

Performance Objectives: P02-P05¥

\begin{tabular}{|c|c|c|}
\hline Change objectives & Implementation strategies & Theoretical construct used to inform strategy development \\
\hline $\begin{array}{l}\text { Knowledge: K1-K6§ } \\
\text { Skills: S1-S3§ } \\
\text { Beliefs: B1-B10§ } \\
\text { Environment: E1-E8§ }\end{array}$ & $\begin{array}{l}\text { See implementation strategies for Reach above plus: } \\
\text { Public commitment to implement FootyFirst signed by senior coach and } \\
\text { club administrator } \\
\text { Development of FootyFirst programme content and resources to meet } \\
\text { context-specific requirements (eg, available time, resources, skills and } \\
\text { experience) } \\
\text { Distribution of FootyFirst resources to senior coaches including: } \\
\text { - FootyFirst coaching manual and CD } \\
\text { - FootyFirst posters } \\
\text { - FootyFirst DVD and online video } \\
\text { Training for coaches in delivery of FootyFirst } \\
\text { Offer of mentoring for coaches in implementation of FootyFirst }\end{array}$ & $\begin{array}{l}\text { See construct use for Reach above plus: } \\
\text { Competency Driver: training and coaching (ID) } \\
\text { Leadership Driver: technical and adaptive leadership (ID) } \\
\text { Opinion leaders: high profile, respected and locally relevant } \\
\text { strength and conditioning coaches employed as FootyFirst } \\
\text { mentors (DOI) }\end{array}$ \\
\hline
\end{tabular}

Implementation

Performance Objectives: P06-P08ף

\begin{tabular}{|c|c|c|}
\hline Change objectives & Implementation strategies & Theoretical construct used to inform strategy development \\
\hline $\begin{array}{l}\text { Knowledge: } \\
\text { K7-K11** } \\
\text { Skills: S4-S8** } \\
\text { Beliefs: B11-B17** } \\
\text { Environment: } \\
\text { E9-E15** }\end{array}$ & $\begin{array}{l}\text { See implementation strategies for Reach and Adoption above plus: } \\
\text { Ongoing mentoring for coaches in implementation of FootyFirst } \\
\text { including: } \\
\text { - Regular contact with coaches using preferred method of } \\
\text { communication } \\
\text { - Audit and feedback of coach implementation of FootyFirst } \\
\text { - Individualised support and coaching to address identified } \\
\text { barriers to high fidelity implementation of FootyFirst } \\
\text { Access to, and support to implement an injury surveillance system } \\
\text { Automated text messaging to remind coaches to implement } \\
\text { FootyFirst } \\
\text { FootyFirst Twitter account highlighting injury prevention and } \\
\text { performance benefits of implementing FootyFirst } \\
\text { Encouragement of club administrators to oversee and monitor } \\
\text { FootyFirst implementation }\end{array}$ & $\begin{array}{l}\text { See construct use for Reach and Adoption above plus: } \\
\text { Organisational drivers: decision support data systems, facilitative } \\
\text { administrative supports and systems interventions (ID) }\end{array}$ \\
\hline
\end{tabular}

*Cross-referenced to the performance objectives in table 2 for details.

tCross-referenced to the change objectives in table 2 for details.

¥Cross-referenced to the performance objectives in table 3 for details.

$\S$ Cross-referenced to the change objectives in table 3 for details.

ICross-referenced to the performance objectives in table 4 for details.

${ }^{*}$ Cross-referenced to the change objectives in table 4 for details.

AF, Australian football; DOI, Diffusion of Innovations theory; ID, Implementation Drivers.

perceived to be compatible with their personal and organisational missions, values and priorities, would enhance the likelihood that FootyFirst would be adopted and implemented by the targeted football coaches and clubs.
Models to translate research to practice can be complex, overly academic and time-consuming when applied in real world settings. ${ }^{35}$ However, this case study shows that by deconstructing the process into a series of straightforward key 
questions to be answered (see table 1), it can be relatively efficient and easy to use IM Step 5 to plan the implementation of injury prevention interventions. This was further facilitated by our previous experience using IM Step 5 in a similar setting. ${ }^{25}$ Nonetheless, the implementation planning process used was more time-consuming than the processes previously used by the administrators of the targeted AF league. For example, convening an IAG, and reviewing and contributing to implementation planning documents were tasks that the league administrators had not previously undertaken. Importantly, the implementation planning process described in this paper could be applied to other injury prevention research and practice settings. In particular, setting-specific and intervention-specific versions of the 'key questions' included in table 1 could easily be applied to generate useful, context-specific information to guide the selection of implementation strategies in other settings and with other injury topics. Clearly, the time and resources committed to this process should be commensurate with the scale and size of the project being undertaken.

Other challenges we experienced revolved around the two related issues of the seasonal and volunteer nature of Australian community sport. As the majority of IAG members were busy volunteers at community sports clubs, it was difficult to recruit and engage them before the start of the AF season when most of the implementation planning needed to be done. Many were actively involved in other sports or did not want to get involved in AF-related activities during the off-season. Once the AF season started, it was difficult to find mutually convenient times for all IAG members to meet as many were heavily involved in the considerable tasks of administering or coaching community sport. Strategies used to address this challenge included: the league administrators and a high profile local sports medicine physician (rather than the research team) sending the invitations to join the IAG; clearly specifying the limited time demands that would be made on members of the IAG; negotiating convenient times and venues for IAG meetings to facilitate maximum participation by members; and using email and telephone conversations to get input from IAG members who were unable to attend meetings.

The language of implementation planning, health promotion and behaviour change theory also challenged the IAG as it is very different to the language of community sport. Fortunately, the first two IM core processes-posing planning problems as questions (see table 1) and brainstorming answers using planning group knowledge and experience-are very practical and participatory. This meant that it was possible to frame the whole implementation planning process in the context of the everyday experiences of the IAG members very early in the process.

Full evaluations of the effectiveness, cost-effectiveness and other outcomes, of the implementation planning process, based on the Reach, (perceived) Effectiveness, Adoption, Implementation and Maintenance (RE-AIM) framework, ${ }^{26}$ and FootyFirst in terms of its population level impact on LLIs in community-AF are currently underway. Based on the outcomes available to date, the Australian Football League has now endorsed the national roll-out of FootyFirst for 2016. This roll-out will be informed by the process described in this paper.

\section{CONCLUSION}

Injury prevention programme outcomes are determined by a combination of the effectiveness of the programme and the effectiveness of its implementation. IM Step 5 is a practical, useful and scalable implementation planning protocol that, when used creatively and flexibly, can lead to the development of theory-informed and evidence-informed, and context-specific implementation plans for injury prevention programmes. Our experience demonstrates the critical importance of researchers, practitioners and community end users collaborating early in the implementation planning process. Even when applied to sport, a setting largely unfamiliar with health promotion concepts, this case study demonstrates that IM Step 5 encourages the use of processes that place equal value on the knowledge, skills and experience that these different groups bring to the implementation planning process.

\section{What is already know on this subject}

- Programme impact is a function of the efficacy of the programme and the effectiveness of its implementation.

- Although many evidence-based sports injury prevention interventions are available, few are well implemented in the real world.

\section{What this study adds}

- High quality implementation planning can be achieved with a strategic, ecological approach based on a partnership between programme developers (researchers) and programme implementers (gatekeepers and end users).

- Intervention Mapping Step 5 is a useful, feasible and scalable protocol to use when planning the implementation of injury prevention interventions.

Twitter Follow Alex Donaldson at @AlexDonaldson13 and Caroline Finch at @CarolineFinch

Acknowledgements The authors thank the Australian football coaches, players and administrators who assisted in the developing the FootyFirst implementation plan outlined in this study.

Contributors All authors contributed to the writing and critical review of this manuscript. $A D$ was responsible for managing the implementation planning process and liaising with the Implementation Advisory Group. Final approval of the contents of the manuscript was obtained from all authors. All authors take responsibility for the integrity of the work from conception to publication.

Funding This study was funded by a National Health and Medical Research Council (NHMRC) Partnership Project Grant (ID 565907) with additional support (in cash and in kind) from the project partner agencies: the Australian Football League (AFL); Victorian Health Promotion Foundation (VicHealth); NSW Sporting Injuries Committee (NSWSIC); JLT Sport, a division of Jardine Lloyd Thompson, Australia; the Department of Planning and Community Development; Sport and Recreation Victoria Division (SRV); and Sports Medicine Australia National and Victorian Branches (SMA). AD's salary was funded by this research grant. CFF was supported by an NHMRC Principal Research Fellowship (ID1058737). BJG was supported by an NHMRC Career Development Fellowship (ID1048731). JC was supported by an NHMRC practitioner fellowship (ID058493). The Australian Centre for Research into Injury in Sport and its Prevention (ACRISP) is one of the International Research Centres for the Prevention of Injury and Protection of Athlete Health supported by the International Olympic Committee (IOC).

Competing interests None declared.

Ethics approval Monash University Human Research Ethics Committee.

Provenance and peer review Not commissioned; externally peer reviewed.

Open Access This is an Open Access article distributed in accordance with the Creative Commons Attribution Non Commercial (CC BY-NC 4.0) license, which permits others to distribute, remix, adapt, build upon this work non-commercially, and license their derivative works on different terms, provided the original work is properly cited and the use is non-commercial. See: http://creativecommons.org/ licenses/by-nc/4.0/ 


\section{REFERENCES}

1 Finch C. A new framework for research leading to sports injury prevention. J Sci Med Sport 2006;9:3-9.

2 Durlak J, DuPre E. Implementation matters: a review of research on the influence of implementation on program outcomes and the factors affecting implementation. Am J Community Psychol 2008;41:327-50.

3 Green LW. From research to "Best Practices" in other settings and populations. Am J Health Behav 2001:25:165-78.

4 Klesges LM, Estabrooks PA, Dzewaltowski DA, et al. Beginning with the application in mind: Designing and planning health behavior change interventions to enhance dissemination. Ann Behav Med 2005:29:66-75.

5 Caburnay CA, Kreuter MW, Donlin MJ. Disseminating effective health promotion programs from prevention research to community organizations. J Public Health Manag Pract 2001;7:81-9.

6 Verhagen E, Bolling C, Finch CF. Caution this drug may cause serious harm! Why we must report adverse effects of physical activity promotion. Br J Sports Med 2015:49:1-2.

7 Hanson D, Allegrante JP, Sleet DA, et al. Research alone is not sufficient to prevent sports injury. Br J Sports Med 2014;48:682-4.

8 Twomey $D$, Finch $C$, Roediger $E$, et al. Preventing lower limb injuries: Is the latest evidence being translated into the football field? J Sc Med Sport 2009;12:452-6.

9 Hollis SJ, Stevenson MR, McIntosh AS, et al. Compliance with return-to-play regulations following concussion in Australian schoolboy and community rugby union players. Br J Sports Med 2012:46:735-40.

10 Norcross $M$, Johnson $S$, Hoffman $M$. The prevalence of injury prevention program use by high school teams. Br J Sports Med 2014;48:645.

11 Bahr R, Thorborg K, Ekstrand J. Evidence-based hamstring injury prevention is not adopted by the majority of Champions League or Norwegian Premier League football teams: the Nordic Hamstring survey. Br J Sports Med 2015;49:1466-71.

12 Klugl M, Shrier I, McBain K, et al. The prevention of sport injury: an analysis of 12 000 published manuscripts. Clin J Sport Med 2010;20:407-12

13 O'Brien J, Finch CF. A systematic review of core implementation components in team ball sport injury prevention trials. Inj Prev 2014;20:357-62.

14 Donaldson A, Finch CF. Applying implementation science to sports injury prevention. Br J Sports Med 2013:47:473-5.

15 Stevenson MR, Hamer $P$, Finch $C F$, et al. Sport, age, and sex specific incidence of sports injuries in Western Australia. Br J Sports Med 2000:34:188-94.

16 Flood L, Harrison J. Hospitalised sports injury, Australia 2002-03. Injury Research and Statistics Series Number 27. Flinders University, Adelaide: Australian Institute of Health and Welfare, 2006:6-23.

17 Finch $C F$, Gabbe $B$, White $P$, et al. Priorities for investment in injury prevention in community Australian Football. Clin J Sport Med 2013;23:430-8.

18 Andrew N, Gabbe BJ, Cook J, et al. Could targeted exercise programmes prevent lower limb injury in community Australian football? Sports Med 2013:43:751-63.

19 Finch CF, Gabbe BJ, Lloyd DG, et al. Towards a national sports safety strategy: addressing facilitators and barriers towards safety guideline uptake. Inj Prev 2011;17:e4.

20 Donnelly CJ, Elliott BC, Ackland TR, et al. An anterior cruciate ligament injury prevention framework: incorporating the recent evidence. Res Sports Med 2012:20:239-62.

21 Donaldson A, Cook J, Gabbe B, et al. Bridging the gap between content and context: establishing expert consensus on the content of an exercise training program to prevent lower-limb injuries. Clin J Sport Med 2015;25:221-9.

22 Finch CF, Twomey DM, Fortington LV, et al. Preventing Australian football injuries with a targeted neuromuscular control exercise programme: comparative injury rates from a training intervention delivered in a clustered randomised controlled trial. Injury Prev 2015; Published Online First: 23 September 2015.

23 Brussoni $M$, Towner $E$, Hayes M. Evidence into practice: combining the art and science of injury prevention. Injury Prev 2006;12:373-7.

24 Bartholomew LK, Parcel GS, Kok G, et al. Planning health promotion programs. An intervention mapping approach. 3rd edn. San Francisco: Jossey-Bass, 2011.

25 Poulos RG, Donaldson A. Improving the diffusion of safety initiatives in community sport. J Sci Med Sport 2015;18:139-44.

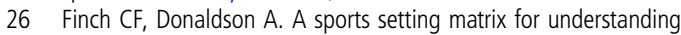
the implementation context for community sport. Br J Sports Med 2010:44:973-8

27 Donaldson A, Leggett S, Finch CF. Sports policy development and implementation in context: Researching and understanding the perceptions of community end-users. Int Rev Sociol Sport 2012;47:743-60.

28 Baranowski T, Perry C, Parcel G. How individuals, environments, and health behavior interact. Social Cognitive Theory. In: Glanz K, Rimer B, Marcus Lewis F, eds. Health behavior and health education theory, research and practice. 3rd edn. San Francisco: Jossey-Bass, 2002:165-84.

29 Gianotti S, Hume PA, Tunstall H. Efficacy of injury prevention related coach education within netball and soccer. J Sci Med Sport 2010;13:32-5.

30 Steffen $\mathrm{K}$, Meeuwisse WH, Romiti M, et al. Evaluation of how different implementation strategies of an injury prevention programme (FIFA 11+) impact team adherence and injury risk in Canadian female youth football players: a cluster-randomised trial. Br J Sports Med 2013:47:480-7.

31 Saunders N, Otago L, Romiti M, et al. Coaches' perspectives on implementing an evidence-informed injury prevention programme in junior community netball. $\mathrm{Br} J$ Sports Med 2010;44:1128-32.

32 Bizzini $M$, Junge A, Dvorak J. Implementation of the FIFA 11+ football warm up program: How to approach and convince the Football associations to invest in prevention. Br J Sports Med 2013;47:803-6.

33 Chalmers DJ, Simpson JC, Depree R. Tackling Rugby injury: lessons learned from the implementation of a five-year sports injury prevention program. I Sci Med Sport 2004:7:74-84

34 Tabak RG, Khoong EC, Chambers DA, et al. Bridging research and practice: models for dissemination and implementation research. Am J Prev Med 2012;43:337-50.

35 Glasgow RE, Green LW, Taylor MV, et al. An evidence integration triangle for aligning science with policy and practice. Am J Prev Med 2012;42: 646-54.

36 Rogers E. Diffusion of innovations. 5th edn. New York, NY: Free Press, 2003

37 Blase K, Van Dyke M, Fixsen D, et al. Implementation science: key concepts, themes, and evidence for practitioners in educational psychology. In: Kelly $B$, Perkins D, eds. Handbook of implementation science for psychology in education. London: Cambridge University Press, 2012:13-34.

38 Frank BS, Register-Mihalik J, Padua DA. High levels of coach intent to integrate a $A C L$ injury prevention program into training does not translate to effective implementation. J Sci Med Sport 2015;18:400-6.

39 Meyers DC, Durlak JA, Wandersman A. The quality implementation framework: a synthesis of critical steps in the implementation process. Am J Community Psychol 2012:50:462-80.

40 Simpson J, Chalmers D, Waller A. The New Zealand Rugby Injury and Performance Project: developing 'Tackling Rugby Injury', a national injury prevention program Health Promot J Austr 2002:13:44-50.

41 Padua DA, Frank B, Donaldson A, et al. Seven steps for developing and implementing a preventive training program: Lessons learned from JUMP-ACL and beyond. Clin Sports Med 2014;33:615-32. 